\title{
Force Prediction Model for Milling 618 Stainless Steel Using Response Surface Methodology
}

\author{
K. Kadirgama and K.A. Abou-El-Hossein \\ Department of Mechanical Engineering, \\ Universiti Tenaga Nasional, 43009, Kajang, Malaysia
}

\begin{abstract}
This paper describes the development of a response model (cutting force) for milling 618 stainless steel utilizing response surface methodology. The cutting force model is developed in terms of cutting speed, feed rate, axial depth and radial depth. The cutting force contours have been generated from these model equations and are shown of different plots. The model generated show that the cutting force reaches the maximum value when cutting speed decreased and, feed rate, axial depth and radial depth are increased. The second order is more accurate based on the variance analysis and the predicted value is closer to the experimental result.
\end{abstract}

Key words: Cutting force, surface response methodology, first order

\section{INTRODUCTION}

In order to get the adequate model that related the cutting force and the cutting parameters (cutting speed, feed rate, axial depth and radial depth), a large number of experiments needed, that is different tests for each and every combination of cutting tool and work-piece material. In this paper, several of cutting speed, feed rate, axial depth and radial depth been takes into account and predicts the cutting force.

In this work, experimental results were used for modeling using response surface methodology $(\mathrm{RSM})^{[1]}$. The RSM is practical, economical and relatively easy to use and it was used by a lot of researchers for modelling machining processes ${ }^{[2-4]}$. Mead and Pike ${ }^{[5]}$ and Hill and Hunter ${ }^{[6]}$ reviewed the earliest work on response surface methodology. Response surface methodology (RSM) is a combination of experimental and regression analysis and statistical inferences. The concept of a response surface involves a dependent variable y called the response variable and several independent variables $\mathrm{x} 1, \mathrm{x} 2, \ldots, \mathrm{xk}^{[7]}$.

Response model: If all of these variables are assumed to be measured, the response surface can be expressed as:

$\mathrm{y}=\mathrm{f}(\mathrm{x} 1 ; \mathrm{x} 2 ; \ldots ; \mathrm{xk})$

The goal is to optimize the response variable y. It is assumed that the independent variables are continuous and controllable by the experimenter with negligible error. The response or the dependent variable is assumed to be a random variable. Say in a milling operation, it is necessary to find a suitable combination of cutting speed $\left(x_{1}=\ln V\right)$, feed $\left(x_{2}=\ln f\right)$, axial depth $\left(\mathrm{x}_{3}=\ln \mathrm{a}_{\mathrm{x}}\right)$ and radial $\operatorname{depth}\left(\mathrm{x}_{4}=\ln \mathrm{a}_{\mathrm{r}}\right)$ that optimize cutting force $(y=\ln F)$. The observed response $y$ as a function of the speed, feed, axial depth and radial depth can be written as

$y=f\left(x_{1}, x_{2}, x_{3}, x_{4}\right)+\varepsilon$

Usually a low order polynomial (first-order and second-order) in some regions of the independent variables is employed. The first-order model,

$$
y=\beta_{o}+\sum_{i=1}^{k} \beta_{i} x_{i}+\varepsilon
$$

and the second -order model,

$$
y=\beta_{o}+\sum_{i=1}^{k} \beta_{i} x_{i}+\sum_{i=1}^{k} \beta_{i i} x_{i}^{2}+\sum_{i} \sum_{j} \beta_{i j} x_{i} x_{j}+\varepsilon
$$

for $\mathrm{i}<\mathrm{j}$

are generally utilized in RSM problems. The $\beta$ parameters of the polynomials are estimated by the method of least squares.

The proposed relationship between the machining responses (cutting force) and machining independent variables can be represented by the following:

$\mathrm{F}=\mathrm{C}\left(\mathrm{V}^{\mathrm{m}} f^{\mathrm{n}} \mathrm{A}_{\mathrm{x}}^{\mathrm{y}} \mathrm{A}_{\mathrm{r}}^{\mathrm{z}}\right) \varepsilon^{\prime}$

Where $\mathrm{F}$ is the cutting force in $\mathrm{N}, \mathrm{V}, f, \mathrm{~A}_{\mathrm{x} \text { and }} \mathrm{A}_{\mathrm{r}}$ are the cutting speed $\left(\mathrm{m} \mathrm{s}^{-1}\right)$, feed rate $\left(\mathrm{mm} \mathrm{rev}^{-1}\right)$, axial depth $(\mathrm{mm})$ and radial depth $(\mathrm{mm})$. C, m, n, y and $\mathrm{z}$ are the constants. Equation (1) can be written in the following logarithmic form:

Corresponding Author: K. Kadirgama, Department of Mechanical Engineering, Universiti Tenaga Nasional, 43009, Kajang, Malaysia 
$\ln F=\ln C+m \ln V+n \ln f+y \ln A_{x}+z \ln A_{r}+\ln \mathcal{E}^{\prime}$

Equation (2) can be written as a linear form:

$y=\beta_{0} x_{0}+\beta_{1} x_{1}+\beta_{2} x_{2}+\beta_{3} x_{3}+\beta_{4} x_{4}+\varepsilon$

where, $\mathrm{y}$ is the cutting force, $\mathrm{x}_{0}=1$ (dummy variables), $\mathrm{x}_{1}=\ln \mathrm{V}, \mathrm{x}_{2}=\ln f, \mathrm{x}_{3}=\ln \mathrm{A}_{\mathrm{x}}, \mathrm{x}_{4}=\ln \mathrm{A}_{\mathrm{r}}$ and $\varepsilon=\ln$ $\varepsilon$,where $\varepsilon$ is assumed to be normally-distributed uncorrelated random error with zero mean and constant variance, $\beta_{0}=\ln C$ and $\beta_{1}, \beta_{2}, \beta_{3}$ and $\beta_{4}$ are the model parameters. The second model can be expressed as:

$\mathrm{y}^{\prime \prime}=\beta_{0} \mathrm{x}_{0}+\beta_{1} \mathrm{x}_{1}+\beta_{2} \mathrm{x}_{2}+\beta_{3} \mathrm{x}_{3}+\beta_{4} \mathrm{x}_{4}+\beta_{11} \mathrm{x}^{2}{ }_{1}+$

$\beta_{22} x^{2}{ }_{2}+\beta_{33} X^{2}{ }_{3}+\beta_{44} x^{2}{ }_{4}+\beta_{11} X_{1} X_{2}+$

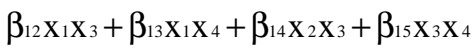

The values of $\beta_{1}, \beta_{2}, \beta_{3}$ and $\beta_{4}$ are to be estimated by the method of least squares. The basic formula is:

$\left(x^{T} x\right) \beta=x^{T} y \quad \beta=\left(x^{T} x\right)^{-1} x^{T} y$

where, $\mathrm{x}^{\mathrm{T}}$ is the transpose of the matrix $\mathrm{x}$ and $\left(\mathrm{x}^{\mathrm{T}} \mathrm{x}\right)^{-1}$ is the inverse of the matrix $\left(\mathrm{x}^{\mathrm{T}} \mathrm{x}\right)$. The details of the solution by this matrix approach are explained in $^{[1,8]}$. The parameters have been estimated by the method of least-square using a Matlab computer package.

Experimental design: To develop the first-order, a design consisting 27 experiments was conducted. BoxBehnken Design is normally used when performing nonsequential experiments. That is, performing the experiment only once. These designs allow efficient estimation of the first and second -order coefficients. Because Box-Behnken Design has fewer design points, they are less expensive to run than central composite designs with the same number of factors. Box-Behnken Design does not have axial points, thus can be sure that all design points fall within the safe operating. BoxBehnken Design also ensures that all factors are never set at their highest levels simultaneously ${ }^{[9-11]}$. Figure 1 shows the 3 factors Box-Behnken. Preliminary tests were carried out to find the suitable cutting speed, federate, axial depth and radial depth as shown in Table 1.

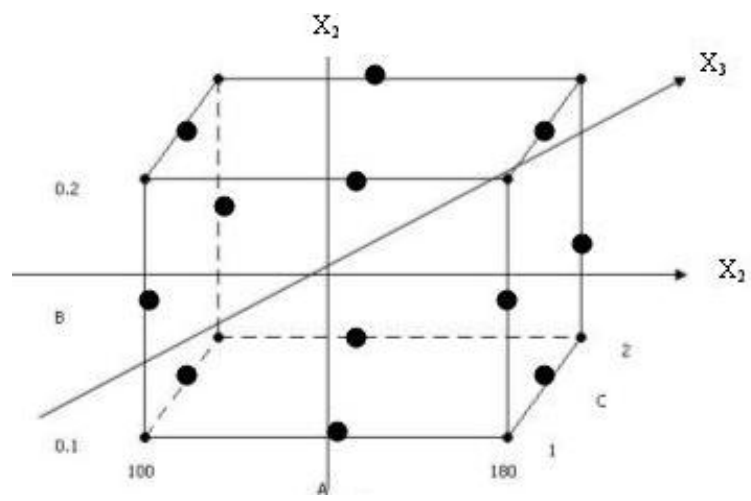

Experimental details: The 618 stainless steel workpieces were provided in the fully annealed condition in sizes of $65 \times 170 \mathrm{~mm}$ and produce by Sanyo Special Steel Co. Ltd.. The tools used in this study are carbide inserts PVD coated with one layer of TiN. The inserts are manufactured by Kennametal with ISO designation of $\mathrm{KC} 735 \mathrm{M}$.They are specially developed for milling applications where stainless steel is the major machined material.

Everyone passes (one pass is equal to $85 \mathrm{~mm}$ ), the cutting test were stopped. The same experiment has been repeated for 3 times to get a more accurate result. Table 2 shows the experimental cutting conditions together with the measured torque.

\section{RESULTS AND DISCUSSION}

First-order model: The cutting force first order model is:

$\mathrm{y}=5.3715-0.1308 \mathrm{x}_{1}+0.3017 \mathrm{x}_{2}$

$+0.2583 \mathrm{x}_{3}+0.2592 \mathrm{x}_{4}$

Table 3 shows the 95\% confidence interval for the experiments. The analysis of variance is shown in Table 4. For the linear model, the p-value for lack of fit is 0.144 and the F-statistics are 6.38. Therefore, the model is adequate.

The levels of independent variables and coding identifications used in this design are presented in Table 1. Table 2 shows the experimental conditions and results obtained from experiments. The transforming equations for each of the independent variables are:

$x_{1}=\frac{\ln (V)-\ln (v) \text { centre }}{\ln (v) h i g h-\ln (v) \text { centre }}$

$x_{2}=\frac{\ln (f)-\ln (f) \text { centre }}{\ln (f) \text { high }-\ln (f) \text { centre }}$

$x_{3}=\frac{\ln \left(A_{x}\right)-\ln \left(a_{x}\right) \text { centre }}{\ln \left(a_{x}\right) \text { high }-\ln \left(a_{x}\right) \text { centre }}$

$x_{4}=\frac{\ln \left(A_{r}\right)-\ln \left(a_{r}\right) \text { centre }}{\ln \left(a_{r}\right) \text { high }-\ln \left(a_{r}\right) \text { centre }}$

Equation (10) describing the cutting force model can be transformed using Equation (11) into the following form:

$\mathrm{F}=5734.547\left(\mathrm{~V}^{-0.52049} \mathrm{~F}^{1.0487} \mathrm{~A}_{\mathrm{x}}{ }^{0.89787} \mathrm{~A}_{\mathrm{r}}^{0.726722}\right)$

Table 1: Levels of independent variables

\begin{tabular}{|c|c|c|c|}
\hline Levels & Low & Medium & High \\
\hline Coding & -1 & 0 & 1 \\
\hline Speed $\mathrm{v}\left(\mathrm{m} \mathrm{s}^{-1}\right)$ & 100 & 140 & 180 \\
\hline Feed $\mathrm{f}\left(\mathrm{mm} \mathrm{rev}^{-1}\right)$ & 0.1 & 0.2 & 0.3 \\
\hline Axial depth $\mathrm{d}_{\mathrm{a}}(\mathrm{mm})$ & 1 & 1.5 & 2 \\
\hline Radial depth $\mathrm{d}_{\mathrm{r}}(\mathrm{mm})$ & 2 & 3.5 & 5 \\
\hline
\end{tabular}


Am. J. Applied Sci., 2 (8): 1222-1227, 2005

Table 2: Experiment condition and results

\begin{tabular}{|c|c|c|c|c|c|}
\hline Run & Cutting speed $\left(\mathrm{m} \mathrm{s}^{-1}\right)$ & Feed $\left(\mathrm{mm} \mathrm{rev}^{-1}\right)$ & Axial depth(mm) & Radial depth(mm) & Exp.Force $(\mathrm{N})$ \\
\hline 1 & 140 & 0.15 & 1 & 2 & 146.67 \\
\hline 2 & 140 & 0.2 & 1 & 3.5 & 190 \\
\hline 3 & 100 & 0.15 & 1 & 3.5 & 190 \\
\hline 4 & 180 & 0.15 & 1 & 3.5 & 170 \\
\hline 5 & 140 & 0.1 & 1 & 3.5 & 110 \\
\hline 6 & 140 & 0.15 & 1 & 5 & 225 \\
\hline 7 & 100 & 0.15 & 1.5 & 2 & 240 \\
\hline 8 & 140 & 0.1 & 1.5 & 2 & 100 \\
\hline 9 & 100 & 0.2 & 1.5 & 3.5 & 340 \\
\hline 10 & 140 & 0.15 & 1.5 & 3.5 & 220 \\
\hline 11 & 180 & 0.2 & 1.5 & 3.5 & 293.33 \\
\hline 12 & 180 & 0.15 & 1.5 & 2 & 145 \\
\hline 13 & 140 & 0.2 & 1.5 & 2 & 200 \\
\hline 14 & 140 & 0.15 & 1.5 & 3.5 & 325 \\
\hline 15 & 140 & 0.15 & 1.5 & 3.5 & 200 \\
\hline 16 & 180 & 0.1 & 1.5 & 3.5 & 130 \\
\hline 17 & 100 & 0.1 & 1.5 & 3.5 & 190 \\
\hline 18 & 100 & 0.15 & 1.5 & 5 & 340 \\
\hline 19 & 140 & 0.1 & 1.5 & 5 & 210 \\
\hline 20 & 180 & 0.15 & 1.5 & 5 & 240 \\
\hline 21 & 140 & 0.15 & 1.5 & 3.5 & 200 \\
\hline 22 & 140 & 0.15 & 2 & 5 & 350 \\
\hline 23 & 140 & 0.2 & 2 & 3.5 & 350 \\
\hline 24 & 140 & 0.1 & 2 & 3.5 & 200 \\
\hline 25 & 140 & 0.15 & 2 & 2 & 190 \\
\hline 26 & 100 & 0.15 & 2 & 3.5 & 340 \\
\hline 27 & 180 & 0.15 & 2 & 3.5 & 313.33 \\
\hline
\end{tabular}

Table 3: The predicted result of the first order model

\begin{tabular}{|c|c|c|c|c|c|c|}
\hline Run & Cutting speed $\left(\mathrm{m} \mathrm{s}^{-1}\right)$ & Feed rate $\left(\mathrm{mm} \mathrm{rev}^{-1}\right)$ & Axial depth(mm) & Radial depth(mm) & Exp. Force $(\mathrm{N})$ & Pre. Force $(\mathrm{N})$ \\
\hline 2 & 140 & 0.15 & 1 & 2 & 146.67 & 99.13 \\
\hline 7 & 140 & 0.2 & 1 & 3.5 & 190 & 201.30 \\
\hline 11 & 100 & 0.15 & 1 & 3.5 & 190 & 177.37 \\
\hline 14 & 180 & 0.15 & 1 & 3.5 & 170 & 130.62 \\
\hline 19 & 140 & 0.1 & 1 & 3.5 & 110 & 97.31 \\
\hline 21 & 140 & 0.15 & 1 & 5 & 225 & 192.92 \\
\hline 4 & 100 & 0.15 & 1.5 & 2 & 240 & 169.96 \\
\hline 5 & 140 & 0.1 & 1.5 & 2 & 100 & 93.25 \\
\hline 6 & 100 & 0.2 & 1.5 & 3.5 & 340 & 345.15 \\
\hline 9 & 140 & 0.15 & 1.5 & 3.5 & 220 & 214.25 \\
\hline 10 & 180 & 0.2 & 1.5 & 3.5 & 293.33 & 254.18 \\
\hline 12 & 180 & 0.15 & 1.5 & 2 & 145 & 125.17 \\
\hline 15 & 140 & 0.2 & 1.5 & 2 & 200 & 192.90 \\
\hline 22 & 140 & 0.2 & 1.5 & 5 & 325 & 375.42 \\
\hline 24 & 140 & 0.15 & 1.5 & 3.5 & 200 & 214.25 \\
\hline 25 & 180 & 0.1 & 1.5 & 3.5 & 130 & 122.87 \\
\hline 26 & 100 & 0.1 & 1.5 & 3.5 & 190 & 166.84 \\
\hline 8 & 100 & 0.15 & 1.5 & 5 & 340 & 330.79 \\
\hline 17 & 140 & 0.1 & 1.5 & 5 & 210 & 181.48 \\
\hline 18 & 180 & 0.15 & 1.5 & 5 & 240 & 243.60 \\
\hline 22 & 140 & 0.15 & 1.5 & 3.5 & 200 & 214.25 \\
\hline 1 & 140 & 0.15 & 2 & 5 & 350 & 359.48 \\
\hline 3 & 140 & 0.2 & 2 & 3.5 & 350 & 375.08 \\
\hline 13 & 140 & 0.1 & 2 & 3.5 & 200 & 181.31 \\
\hline 16 & 140 & 0.15 & 2 & 2 & 190 & 184.71 \\
\hline 20 & 100 & 0.15 & 2 & 3.5 & 340 & 330.49 \\
\hline 27 & 180 & 0.15 & 2 & 3.5 & 313.33 & 243.38 \\
\hline
\end{tabular}

Table 4: Analysis of variance for Force Fy

\begin{tabular}{|c|c|c|c|c|c|c|}
\hline Source & $\mathrm{DF}$ & Seq SS & Adj SS & Adj MS & $\mathrm{F}$ & $\mathrm{P}$ \\
\hline Regression & 4 & 137461 & 137461 & 34365.2 & 43.77 & $\overline{0.000}$ \\
\hline Linear & 4 & 137461 & 137461 & 34365.2 & 43.77 & 0.000 \\
\hline Residual Error & 22 & 17272 & 17272 & 785.1 & & \\
\hline Lack-of-Fit & 20 & 17005 & 17005 & 850.3 & 6.38 & 0.144 \\
\hline Pure Error & 2 & 267 & 267 & 133.3 & & \\
\hline Total & 26 & 154733 & & & & \\
\hline
\end{tabular}




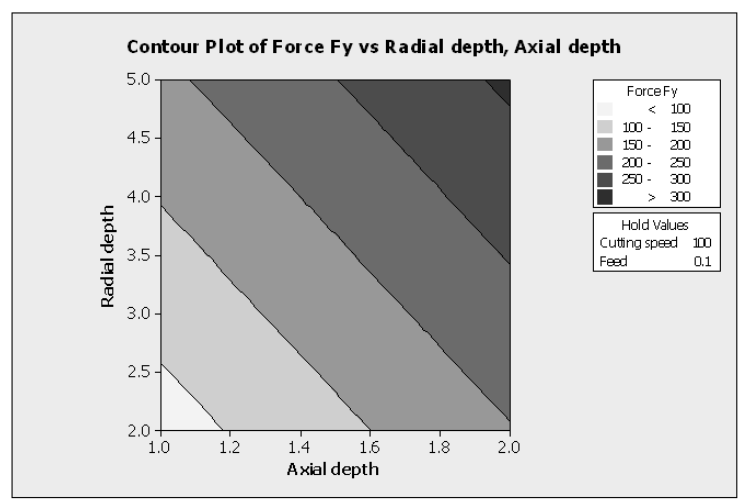

Fig. 2a: Cutting force contours in the Axial depthradial depth plane for cutting speed $100 \mathrm{~m} \mathrm{~s}^{-1}$ and feed rate $0.1 \mathrm{~mm} \mathrm{rev}^{-1}$

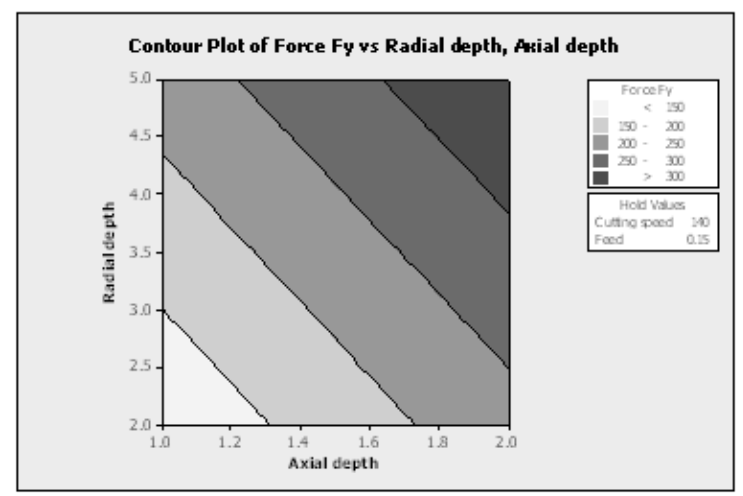

Fig. 2b: Cutting force contours in the Axial depthradial depth plane for cutting speed $140 \mathrm{~m} \mathrm{~s}^{-1}$ and feed rate $0.15 \mathrm{~mm} \mathrm{rev}^{-1}$

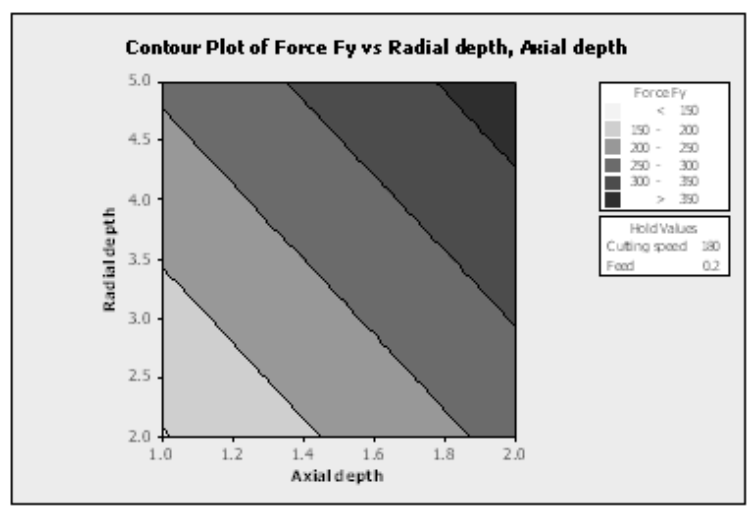

Fig. 2c: Cutting force contours in the Axial depthradial depth plane for cutting speed $180 \mathrm{~m} \mathrm{~s}^{-1}$ and feed rate $0.2 \mathrm{~mm} \mathrm{rev}^{-1}$

This result shows that feed rate has the most significant effect on the cutting force, follow by axial depth, radial depth and cutting speed. The equation shows that the cutting force increasing with reducing the cutting speeds and increasing the feed rate, axial depth and radial depth.

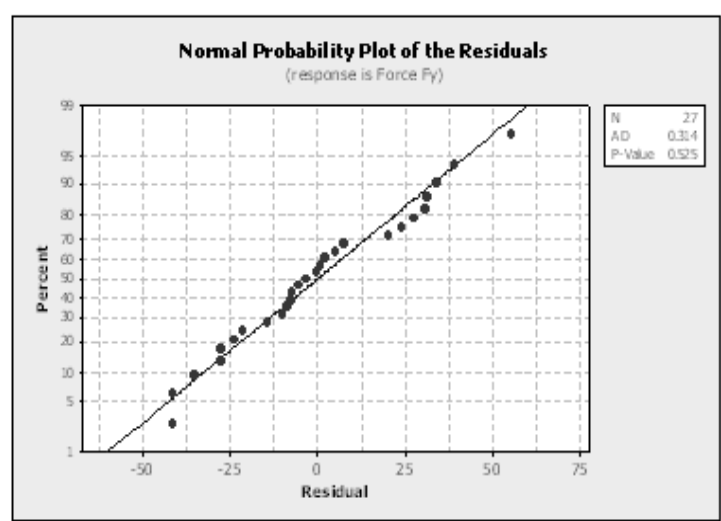

Fig. 3: Normal probability plot of the residuals

Equation (10) is utilized to develop cutting force contour at the selected cutting speed and feed rate. Figure 2 (a) to 2 (c) show the cutting force contour with selected axial depth and radial depth. These contours help to predict the cutting force at any zone of experimental zone. Figure 3 shows that the residual plot is fit to the normal line.

From the contour, the cutting force reaches the highest value at Fig. 1 (c) where the value of cutting speed at its lower value, feed rate, axial depth and radial depth at their maximum value. The cutting force can reach more than $350 \mathrm{~N}$ in Fig. 1 (c) .The lowest cutting force is in Fig. 1 (a) when the cutting speed at its maximum value and the other factors at its maximum value. From this contour plot, the safety zone of cutting force can be selected for any experiment.

The second-order model was postulated in obtaining the relationship between the cutting force and the machine independent variables. The model was based on the Box-Behnken Design method. The model equation is:

$$
\begin{aligned}
& \mathrm{y}^{\prime \prime}=2.05074-0.031 \mathrm{x}_{1}+47.37 \mathrm{x}_{2}+2.97 \mathrm{x}_{3}+1.60 \mathrm{x}_{4}+0.00029 \mathrm{x}_{1}^{2} \\
& -50.17 \mathrm{x}_{2}{ }_{2}-0.78 \mathrm{x}_{3}{ }_{3}-0.14 \mathrm{x}_{4}^{2}-0.29 \mathrm{x}_{1} \mathrm{x}_{2}-0.018 \mathrm{x}_{1} \mathrm{x}_{3}-0.0094 \mathrm{x}_{1} \mathrm{x}_{4} \\
& +24.3 \mathrm{x}_{2} \mathrm{x}_{3}+12.8 \mathrm{x}_{2} \mathrm{x}_{4}+0.80 \mathrm{x}_{3} \mathrm{x}_{4}
\end{aligned}
$$

Table 5 shows the $95 \%$ confidence interval for the experiments. The analysis of variance is shown in Table 6 . For the second-order model, the p-value for lack of fit is 0.221 and the F-statistics are 4.5249. Therefore, the model is adequate. The second-order model is more adequate, because the predicted result is much more accurate than the first model. The p-value show much bigger than the first order. Equation (8) is used to develop the contour plot as shown in Fig. 4 (a) to 4 (c). Figure 5 shows that the residual plot is fit to the normal line. 
Am. J. Applied Sci., 2 (8): 1222-1227, 2005

Table 5: The predicted result of the second order model

\begin{tabular}{|c|c|c|c|c|c|c|}
\hline Run & Cutting speed & Feed rate & Axial depth & Radial depth & Exp.Force(N) & Pre.Force $(\mathrm{N})$ \\
\hline 2 & 140 & 0.15 & 1 & 2 & 146.67 & 130.56 \\
\hline 7 & 140 & 0.2 & 1 & 3.5 & 190 & 202.36 \\
\hline 11 & 100 & 0.15 & 1 & 3.5 & 190 & 220.69 \\
\hline 14 & 180 & 0.15 & 1 & 3.5 & 170 & 165.97 \\
\hline 19 & 140 & 0.1 & 1 & 3.5 & 110 & 110.97 \\
\hline 21 & 140 & 0.15 & 1 & 5 & 225 & 201.11 \\
\hline 4 & 100 & 0.15 & 1.5 & 2 & 240 & 216.81 \\
\hline 5 & 140 & 0.1 & 1.5 & 2 & 100 & 92.92 \\
\hline 6 & 100 & 0.2 & 1.5 & 3.5 & 340 & 324.45 \\
\hline 9 & 140 & 0.15 & 1.5 & 3.5 & 220 & 206.67 \\
\hline 10 & 180 & 0.2 & 1.5 & 3.5 & 293.33 & 273.05 \\
\hline 12 & 180 & 0.15 & 1.5 & 2 & 145 & 161.25 \\
\hline 15 & 140 & 0.2 & 1.5 & 2 & 200 & 211.81 \\
\hline 22 & 140 & 0.2 & 1.5 & 5 & 325 & 330.69 \\
\hline 24 & 140 & 0.15 & 1.5 & 3.5 & 200 & 206.67 \\
\hline 25 & 180 & 0.1 & 1.5 & 3.5 & 130 & 140.00 \\
\hline 26 & 100 & 0.1 & 1.5 & 3.5 & 190 & 204.72 \\
\hline 8 & 100 & 0.15 & 1.5 & 5 & 340 & 330.70 \\
\hline 17 & 140 & 0.1 & 1.5 & 5 & 210 & 196.81 \\
\hline 18 & 180 & 0.15 & 1.5 & 5 & 240 & 270.14 \\
\hline 22 & 140 & 0.15 & 1.5 & 3.5 & 200 & 206.67 \\
\hline 1 & 140 & 0.15 & 2 & 5 & 350 & 360.56 \\
\hline 3 & 140 & 0.2 & 2 & 3.5 & 350 & 355.97 \\
\hline 13 & 140 & 0.1 & 2 & 3.5 & 200 & 194.58 \\
\hline 16 & 140 & 0.15 & 2 & 2 & 190 & 208.33 \\
\hline 20 & 100 & 0.15 & 2 & 3.5 & 340 & 342.64 \\
\hline 27 & 180 & 0.15 & 2 & 3.5 & 313.33 & 281.25 \\
\hline
\end{tabular}

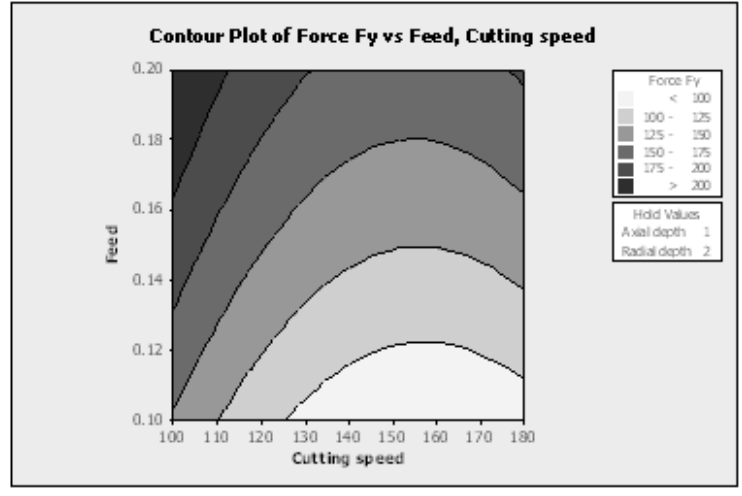

Fig. 4a: Cutting force contours in the Feed rate-cutting speed plane for Axial depth $1 \mathrm{~mm}$ and radial depth $2 \mathrm{~mm}$

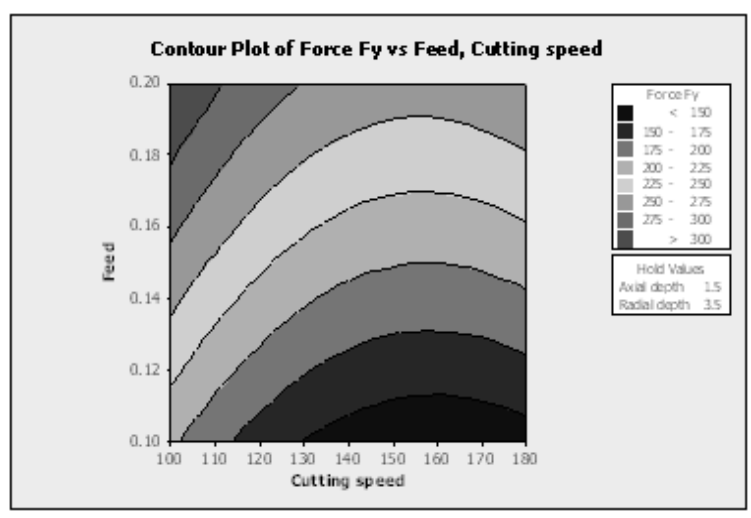

Fig. 4b: Cutting force contours in the feed rate-cutting speed plane for Axial depth $1.5 \mathrm{~mm}$ and radial depth $3.5 \mathrm{~mm}$

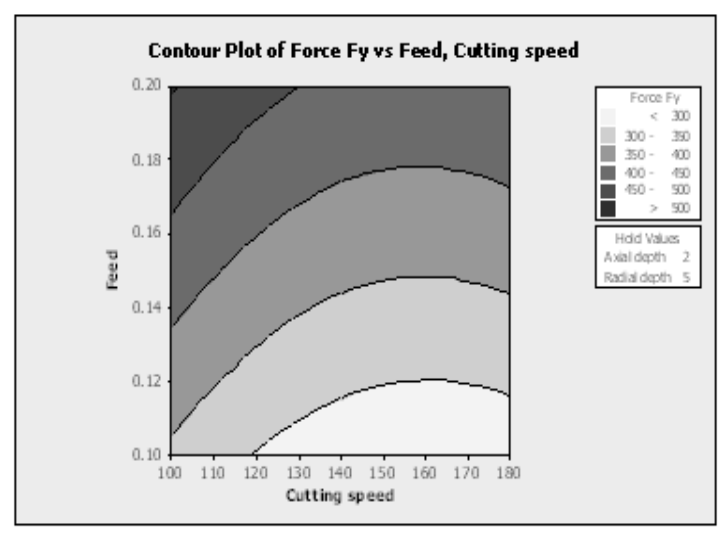

Fig. 4c: Cutting force contours in the feed rate-cutting speed plane for Axial depth $2 \mathrm{~mm}$ and radial depth $5 \mathrm{~mm}$

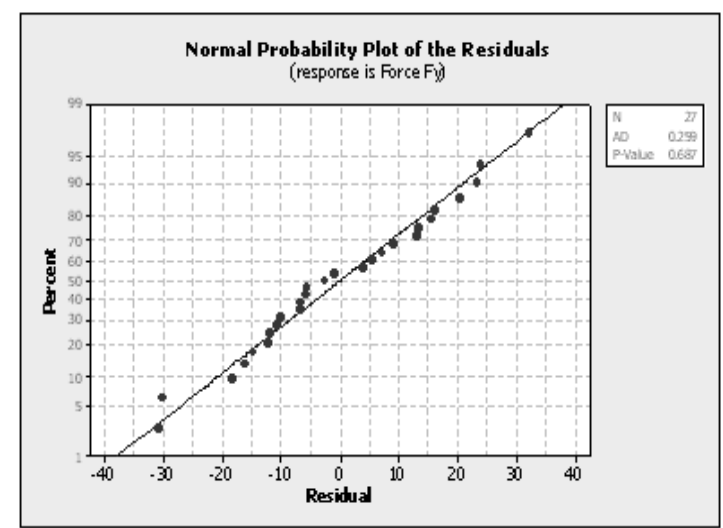


Am. J. Applied Sci., 2 (8): 1222-1227, 2005

Table 6: Analysis of variance for second-order model

\begin{tabular}{lllllll}
\hline Source & DF & Seq SS & Adj SS & Adj MS & F & P \\
\hline Regression & 14 & 447.358 & 447.358 & 31.954 & 1758.88 & 0.000 \\
Linear & 4 & 434.746 & 434.746 & 108.687 & 5982.52 & 0.000 \\
Square & 4 & 2.922 & 2.922 & 0.731 & 40.21 & 0.000 \\
Interaction & 6 & 9.690 & 9.690 & 1.615 & 88.90 & \\
Residual Error & 12 & 0.218 & 0.218 & 0.018 & & \\
Lack-of-Fit & 10 & 0.218 & 0.218 & 0.022 & & 0.221 \\
Pure Error & 2 & 0.000 & 0.000 & 0.00486 & & \\
Total & 26 & 447.576 & & & & \\
\hline
\end{tabular}

\section{CONCLUSION}

Reliable cutting force model has been developed and utilized to enhance the efficiency of the milling 618 stainless steel. The cutting force equation shows that feed rate, cutting speed, axial depth and radial depth play the major role to produce the cutting force. The higher the feed rate, axial depth and radial depth, the cutting force generates very high compared with low value of feed rate, axial depth and radial depth. The contours of the cutting force outputs were constructed in planes containing two of the independent variables. These contours were further developed to select the proper combination of cutting speed, feed, axial depth and radial depth to produce the optimum cutting force. Response surface methodology provides a large amount of information with a small amount of experimentation.

\section{ACKNOWLEDGEMENT}

The financial support by University Tenaga Nasional is gratefully acknowledged.

\section{REFERENCES}

1. Montgomery, D.C., 1984. Design and Analysis of Experiments. 2nd Edn. John Wiley, New York.

2. El Baradie, M.A., 1993. A surface roughness model for turning gray cast iron (154BHN). Proc. Institution of Mechanical Engg, Part B. J. Engineering Manufacture, 207: 43-54.
3. Hasegawa, M., A. Seireg and R.A. Lindberg, 1976. A surface roughness model for turning. Tribology International, pp: 285-289.

4. Sundaram, R.M. and B.K. Lambert, 1981. Mathematical models to predict surface finish in fine turning of steel, Part I. Intl. J. Product. Res., 19: 547-556.

5. Mead, R. and D.J. Pike, 1975. A review of response surface methodology from a biometric viewpoint. Biometrics, 31: 803-851.

6. Hill, W.J. and W.G. Hunter, 1966. A review of response surface methodology: A literature survey. Technometrics, 8: 571-590.

7. Hicks, C.R., 1993. Fundamental Concepts in the Design of Experiments. 4th Edn. Saunders College Publishing, Holt, Rinehart and Winston.

8. Draper, N.R. and H. Smith, 1981. Applied Regression Analysis. Wiley, New York.

9. Box, G.E.P. and N.R. Draper, 1987. Empirical Model-building and Response Surfaces. New York, John Wiley and Sons.

10. Box, G.E.P. and D.W. Behnken, 1960. Some new three level designs for the study of quantitative variables. Technometrics, 2: 455-475.

11. Khuri, A.I. and J.A. Cornell, 1987. Response Surfaces: Designs and Analyses. Marcel Dekker, Inc. 